\title{
SYNTHESIS OF BIPHASIC CALCIUM PHOSPHATE MINERALS FROM SHELLS OF POKER-CHIP VENUS
}

\author{
NGUYEN NGOC MINH \\ School of Materials Science and Engineering, Hanoi University of Science and Technology, \\ No. 1, Dai Co Viet, Hanoi, Vietnam \\ "E-mail: minh.nguyenngoc@hust.edu.vn
}

Submitted May 11, 2021; accepted July 18, 2021

\begin{abstract}
Keywords: Hydroxyapatite, Biphasic calcium phosphate, $\beta$-tricalcium phosphate, Hydrothermal method, Bloceramics
The scientific community is widely interested in synthetic biomaterials, calcium phosphate - based bioceramics, such as biphasic calcium phosphate (BCP), because of its potential applications. Biphasic calcium phosphate (BCP) is known as a bioceramic which is a mixture of hydroxyapatite and $\beta$-tricalcium phosphate in fixed ratios that can be used for a bone substitute. In this research, biphasic calcium phosphate was synthesized from the shell powder of poker-chip venus by using ethyl phosphate as a reducing agent by the aqueous precipitation technique. The sample powder was determined by X-ray diffraction and the morphology of the synthesised powder was determined by field emission scanning electron microscopy while Fourier-transform infrared spectroscopy was used to confirm the chemical bonds in the BCP powder.
\end{abstract}

\section{INTRODUCTION}

Biphasic calcium phosphate (BCP), a bioceramic composed of hydroxyapatite (HA) and $\beta$-tricalcium phosphate $(\beta$-TCP), has been widely used as a scaffold for bone regeneration [1-3]. Both of the calcium phosphate minerals, hydroxyapatite (HA) and tri-calcium phosphate $(\beta$-TCP), have received greater attention due to its bioresorbability and osteoconductive properties.

Hydroxyapatite $\left[\mathrm{Ca}_{10}\left(\mathrm{PO}_{4}\right)_{6}(\mathrm{OH})_{2}, \mathrm{HA}\right]$ is commonly used in bone tissue engineering because of its nonimmunogenic properties, biocompatibility, bioactivity and good bone conductivity [4-5]. HA is also known as a slowly biodegradable material with high osteo-compatibility and bone binding capability. In addition, the resorption rate of $\mathrm{HA}$ is relatively slow compared to the rate of the new bone formation. However, some disadvantages of hydroxyapatite, such as brittleness, low tensile strength and fracture toughness still exist [6]. Therefore, the use of HA sometimes fails to meet the mechanical requirements.

$\beta$-Tricalcium phosphate $\left[\beta-\mathrm{Ca}_{3}\left(\mathrm{PO}_{4}\right)_{2}, \beta\right.$-TCP $]$ is one of the most investigated bioceramics to be used in bone tissue regeneration because of its high biocompatibility, favourable resorption properties, and osteoconductivity [7-9]. In comparison to HA, $\beta$-TCP is less stable, but it has a faster degradation rate and higher solubility [10]. However, $\beta$-TCP still has a few disadvantages, such as its absorption does not completely agree with the new bone absorption. Its mechanical properties are poor with slight brittleness that can make it unstable to work against fatigue [11].

In general, calcium phosphate minerals are mechanically weak and show poor growth resistance compared to other bioceramics like alumina and zirconia which limits their application as load bearing bone substitutes [12]. Thus, a combination of HA and $\beta$-TCP minerals creates biphasic calcium phosphate (BCP) with considerable stability, good resorbability and interaction with bone tissue. The ability of BCP to interact with osteoconductive cells would be greater compared to HA alone [13]. There are several ways to make BCP. It could be synthesised by the simple mixing of HA and $\beta$-TCP [14], precipitation [15], hydrolysis [16], a hydrothermal method [17-18] and a sol-gel method [19]. In this report, biphasic calcium phosphate is synthesised by the hydrothermal method employing shells of poker-chip venus as an excellent source of calcium carbonate and calcium oxide.

\section{EXPERIMENTAL}

Materials and methods

In this research, all the reagents used in the pre-sent study were obtained from HiMedia, India. Firstly, the shells of the poker-chip venus were collected from the sea and cleaned using distilled water. Then, they were dried in air at $90{ }^{\circ} \mathrm{C}$ for $6 \mathrm{~h}$. To get fine powders, these shells were mechanically crushed and ball milled in a 
$350 \mathrm{ml}$ stainless steel jar for 4 hours at $250 \mathrm{rpm}$ using a mixture of three types of crushed balls $(\Phi 5,10$ and $15 \mathrm{~mm})$. The balls are made from tungsten carbide. Following this step, 0.4 gram of this shell powder was added to $40 \mathrm{ml}$ of deionised water while stirring. Then, $690 \mu$ of triethyl phosphate was added to the solution. This solution was then autoclaved in a Teflon lined container at $135{ }^{\circ} \mathrm{C}$ for 12 - 34 hours and furnace cooled. The precipitate, thus obtained, was washed and filtered with distilled water followed by drying at $80{ }^{\circ} \mathrm{C}$ before the subsequent characterisation. The morphology of the synthesised powder was determined using Field emission scanning electron microscopy (FE-SEM, model JEOL JSM-7600F). The X-ray diffraction (XRD) pattern of the synthesised powder was performed with $\mathrm{Cu} \mathrm{K} \alpha$ radiation $(\lambda=1.5406 \AA)$ on an X-ray diffractometer (model D8Advance). The Fourier transform infrared spectroscopy (FT-IR) was performed with a Nexus 6700 FT-IR (Thermo-Nicolet, Inc.) equipped with an attenuated total reflectance (ATR) accessory (Smart Miracle, PIKE Tech.)

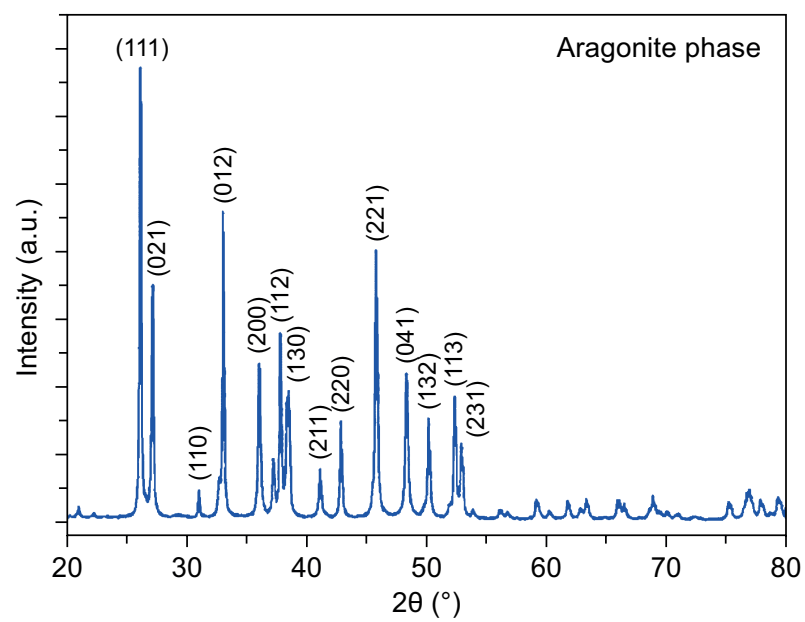

a) XRD pattern

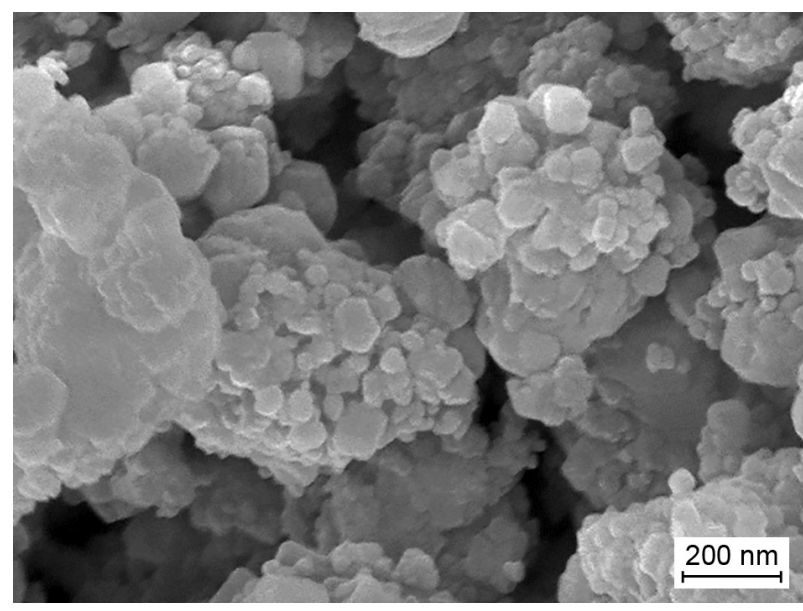

b) SEM image

Figure 1. XRD pattern (a) and SEM image (b) of the shell powders obtained after ball milling.

\section{RESULTS AND DISCUSSION}

Figure 1 shows the XRD pattern of the raw shell powders and SEM image after the ball milling. In Figure 1a, the strongest diffraction peaks correspond to the planes (111), (021), (012), (200), (112), (221), (041) and (113). The peaks were in agreement with the published data [20] and belonged to JCPDS 05-0453. Thereby, the XRD patterns in Figure 1a confirm the presence of calcium carbonate in an aragonite phase [21] in the ball milled shell powders. The SEM image in Figure $1 \mathrm{~b}$ shows that the morphology of the shell fine powders are in a range several micrometres.

Figure 2 shows the XRD patterns of the synthesised BCP powders with different soaking times. As can be observed, the powder consists of both HA and $\beta$-TCP phases. The main cha-racteristic peaks with a high intensity of $\mathrm{HA}$ at the $2 \theta$ diffraction angles $\left(25.82^{\circ}, 31.71^{\circ}\right.$, $32.86^{\circ}, 46.9^{\circ}$, and $49.53^{\circ}$ ), corresponding to (002), (211), (300), (222) and (321) Miller's planes confirmed the formation of hydroxyapatite. The diffraction pattern agreed with the diffraction profiles reported in JCPDF 01-076-0694 for hydroxyapatite [22-23]. The main peaks for $\beta$-TCP at the $2 \theta$ diffraction angles $\left(25.8^{\circ}\right.$, $28.3^{\circ}, 31.8^{\circ}, 34.3^{\circ}, 39.4^{\circ}$ and $\left.46.2^{\circ}\right)$, corresponding to (1010), (214), (0210), (220), (1016) and (4010) Miller and Miller-Bravais's planes, confirmed the successful formation of $\beta$-TCP. This diffraction pattern agreed with the diffraction profiles reported in JCPDF 00-0090169 for $\beta$-TCP [24]. These results show that BCP was successfully synthesised by the hydrothermal method at $135^{\circ} \mathrm{C}$ for $12-34$ hours.

In Figure 3, the FTIR analysis reveals that the synthesised biphasic calcium phosphate shows absorption bands corresponding to the ion $\mathrm{PO}_{4}{ }^{3-}$ around $1085 \mathrm{~cm}^{-1}$, $1021 \mathrm{~cm}^{-1}, 960 \mathrm{~cm}^{-1}, 600 \mathrm{~cm}^{-1}, 564 \mathrm{~cm}^{-1}$ and $473 \mathrm{~cm}^{-1}$ confirmed to the bending $\mathrm{O}-\mathrm{P}-\mathrm{O}$. The absorption bands around $3568 \mathrm{~cm}^{-1}$ and $629 \mathrm{~cm}^{-1}$ were in the presence

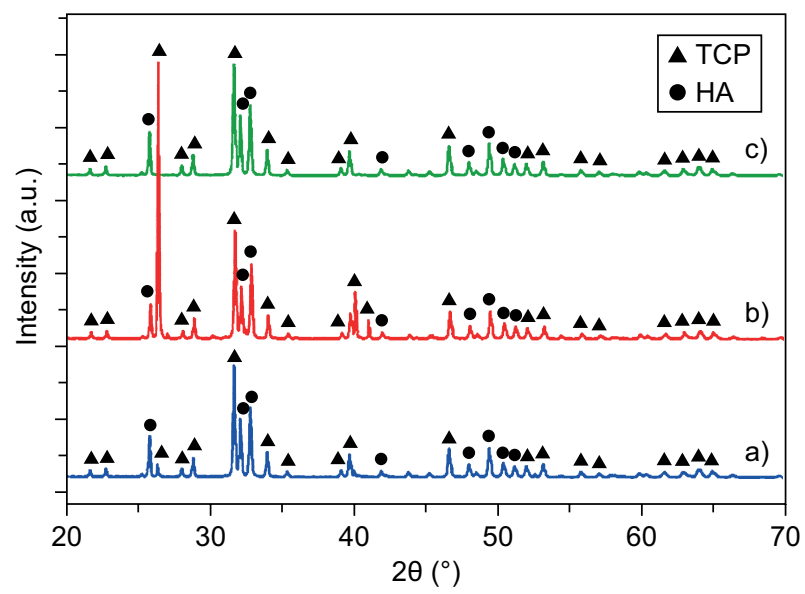

Figure 2. XRD patterns of the BCP powder obtained after hydrothermal treatment at $135^{\circ} \mathrm{C}$ with different soaking times: a) 12 hours, b) 23 hours and c) 34 hours. 
of the $\mathrm{OH}-$ group, these appeared because of the deformation of the $\mathrm{P}-\mathrm{OH}$ vibration. The observed bands were attributed to the $\beta$-TCP and HA powders $[19,25]$.

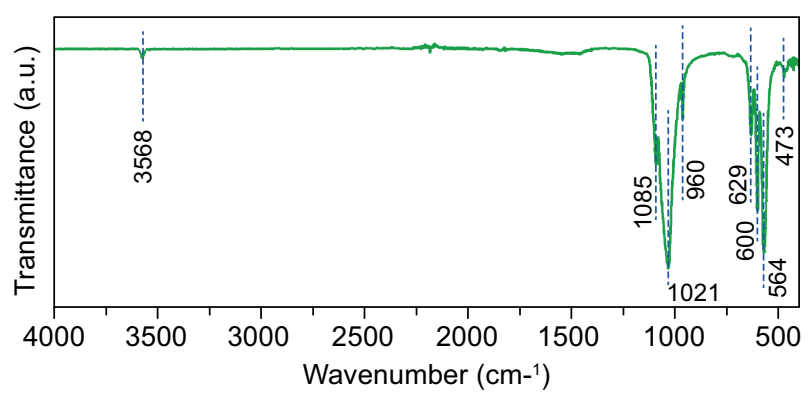

Figure 3. FT-IR spectra of the synthetised biphasic calcium phosphate.

In Figure 4, the SEM images show that the morphology of BCP is rod-like at all times. However, as it can be observed, it was not possible to control the diameter of these rods. It seems that a longer soaking time could lead to the shrinkage of the rod diameter.

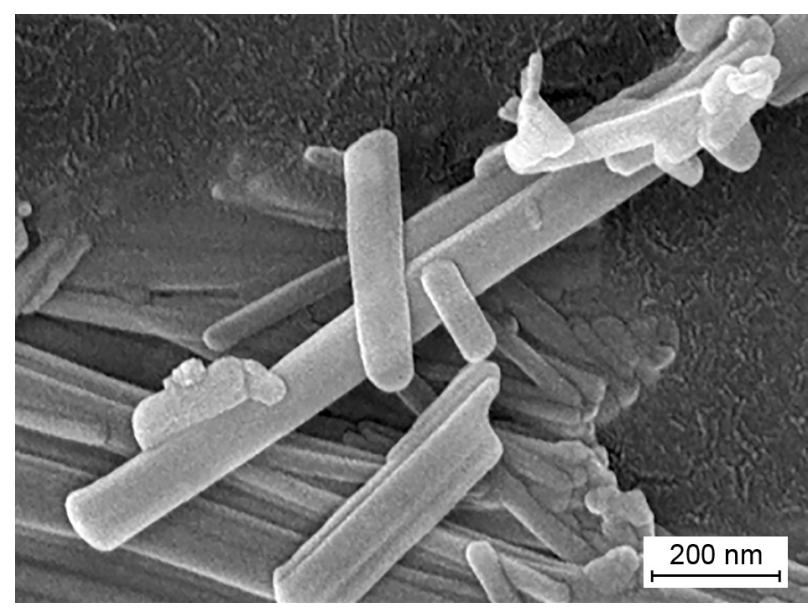

a) 12 hours

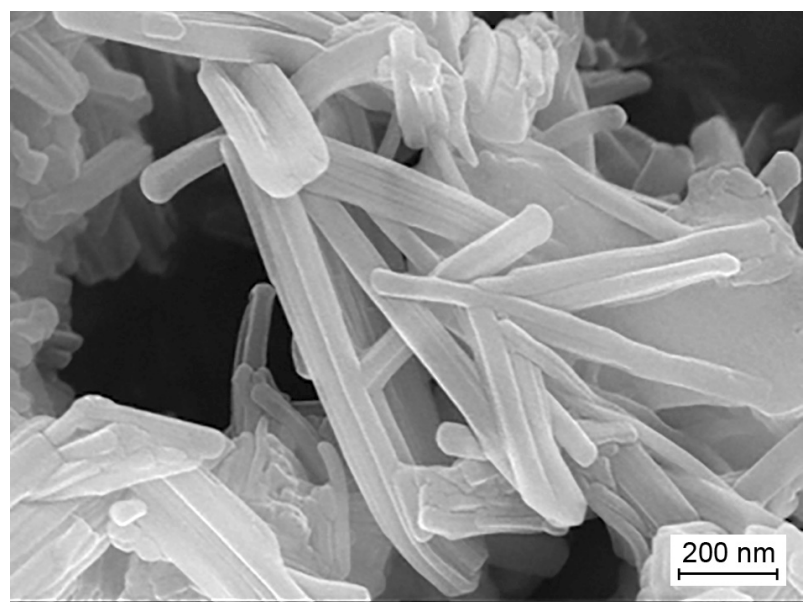

b) 23 hours
In this research, the aspect ratio of the $\mathrm{BCP}$ rods remained almost the same, even the amount of energy provided for the BCP synthesis reactions was increased by extending the soaking time. This may be due to the fact that calcium carbonate powders are insoluble in water. The shell fine powder provides a nucleation site for the growth of the rods. However, the ball milling of the shell did not lead to uniform sized calcium carbonate particles. Therefore, the non-uniform size of these shell powders can lead to the synthesis of rods with various diameters. It also suggests that by using a solvent that would completely dissolve calcium carbonate, we could synthesise BCP rods of a uniform diameter. These low aspect ratio $\mathrm{BCP}$ rods could be used as a coating material which will help in the adhesion of osteoblasts on the surface of load bearing biomaterials, or they could be used as a bone cement.

\section{CONCLUSION}

In this study, shells of the poker-chip venus were used as a rich source of calcium to successfully synthesise biphasic calcium phosphate rods via the hydrothermal method at $135^{\circ} \mathrm{C}$ over 12 - 34 hours. The XRD and FTIR results confirm the presence of the hydroxyapatite and $\beta$-tricalcium phosphate phase in the obtained powders. In addition, the XRD patterns showed that the BCP had good crystallisation, and the SEM micrographs also showed that the diameters of the synthesised BCP rods are nano-sized.

This research could be an economic way to obtain biphasic calcium phosphate $(\mathrm{HA} / \beta-\mathrm{TCP})$ by utilising biowaste.

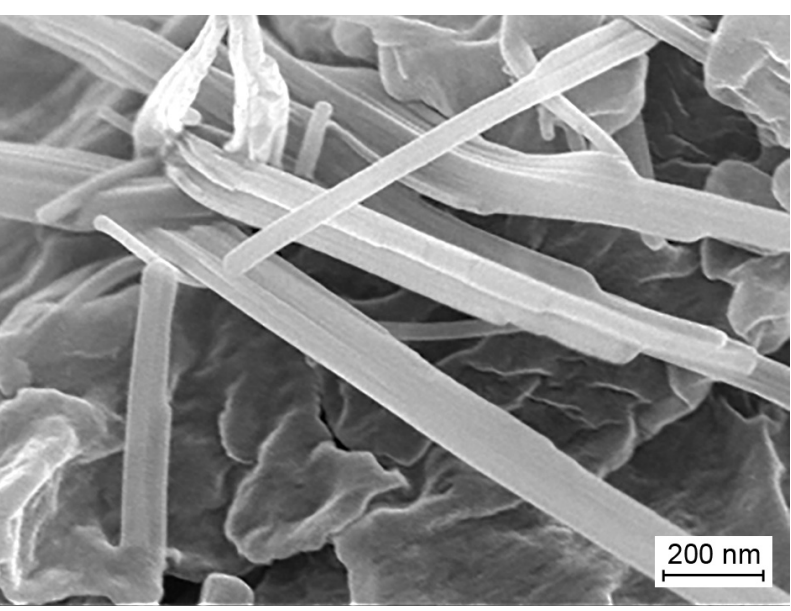

c) 34 hours

Figure 4. SEM Immages of the BCP powders obtained after hydrothermal treatment at $135{ }^{\circ} \mathrm{C}$ for a) 12 hours; b) 23 hours and c) 34 hours. 
Acknowledgments

This work was supported by the Thai Binh Department of Science and Technology under grant number: TB-CT/CN01/19-20.

\section{REFERENCES}

1. Montañez N.D., Estupiñanb H.A., Garcíaa S.J., Peña D.Y. (2018): Fabrication and Characterization of Novel Biphasic Calcium Phosphate and Nanosized Hydroxyapatite Derived from Fish Otoliths in Different Composition Ratios. Chemical Engineering Transactions, 64, 307-312. doi: 10.3303/ CET1864052.

2. Buschmann J. (2016): Biomimetic phosphate nanocomposites for bone-tissue regeneration. Nanocomposites for Musculoskeletal Tissue Regeneration, 285-305. doi: 10.1016/ B978-1-78242-452-9.00013-3.

3. Kohrs N.J., Liyanage T., Venkatesan N., Najarzadeh A., Puleo D.A. (2019): Drug Delivery Systems and Controlled Release. Encyclopedia of Biomedical Engineering, 316-329. doi: 10.1016/B978-0-12-801238-3.11037-2.

4. Shi H., Zhou Z., Li W., Fan Y., Li Z., Wei J. (2021): Hydroxyapatite Based Materials for Bone Tissue Engineering: A Brief and Comprehensive Introduction. Crytals, 11(149), 1-18. doi: 10.3390/cryst11020149.

5. Bui X.V., Thang T.D. (2016): Synthesis of Biphasic Calcium Phosphate and its Behaviour in Simulated Body Fluid. ASEAN Journal on Science and Technology for Development. 33(2), 63-68. doi: 10.29037/ajstd.30.

6. Family R., Hashjin M.S., Nik S.N., Nemati (2012): Surface modification for titanium A. implants by hydroxyapatite nanocomposite, Caspian Journal of Internal Medicine, 3(3), 460-465.

7. Aguilar C.R., Pinto U.O., Reyes E.A.A., Juarez R.L., Lopez I.A., Alfonso I. (2018): Characterization of $\beta$-tricalcium phosphate powders synthesized by sol-gel and mechanosynthesis. Boletín de la Sociedad Española de Cerámica y Vidrio, 57(5), 213-220. doi: 10.1016/j.bsecv. 2018.04.004.

8. Mateescu M., Rguitti E., Ponche A., Descamps M., Anselme K. (2012): Biomimetic evaluation of b tricalcium phosphate prepared by hot isostatic pressing. Biomatter, 2(3), 103-113. doi: 10.4161/biom.21377.

9. Vasudev S., Vakade C.D., Paramesh R.C., Prerna R., Deepak S., Mathew A.E. (2017): Hydroxyapatite and $\beta$-tricalcium Phosphate for Bone Regeneration in Large Cystic Cavities. International Journal of Oral Health and Medical Research, 4(2), 7-11.

10. Saulacic N., Kobayashi M.F., Kimura Y., Bracher A.I., Zimlamnn C., Lang N.P. (2021): The effect of synthetic bone graft substitutes on bone formation inrabbit calvarial defects. Journal of Materials Science: Materials in Medicine, 32(14), 1-13. doi: 10.1007/s10856-020-06483-6.

11. Liu B., Lun D.X. (2012): Current Application of $\beta$-tricalcium Phosphate Composites in Orthopaedics. Orthopaedic Surgery, 4(3), 139-144. doi: 10.1111/j.1757-7861. 2012.00189.x

12. Ye W., Wang X.X. (2007): Ribbon-like and rod-like hydroxyapatite crystals deposited on titanium surface with electrochemical method. Materials Letters, 61, 4062-4065. doi: 10.1016/j.matlet.2007.01.040.
13. Hamadouche M., Sedel L. (2000): Ceramics in orthopaedics. The Journal of Bone and Joint Surgery, 82B(8), 1095-1099. doi: 10.1302/0301-620X.82B8.11744.

14. Nilen R.W.N., Richter P.W. (2008): The thermal stability of hydroxyapatite in biphasic calcium phosphate ceramics. Journal of Materials Science: Materials in Medicine, 19, 1693-1702. doi: 10.1007/s10856-007-3252-x

15. Tilkin R.G., Mahy J.G., Régibeau N., Grandfils C., Lambert S.D. (2019): Optimization of Synthesis Parameters for the Production of Biphasic Calcium Phosphate Ceramics via Wet Precipitation and Sol-Gel Process. Chemistry Select, 4, 6634-6641. doi: 10.1002/slct.201901175

16. Huang C., Cao P., Edmonds N., Tuan X. (2014): Synthesis of biphasic calcium phosphate powders by a simple hydrolysis process. International Journal of Nanotechnology (IJNT), 11, 396-402. doi: 10.1504/IJNT.2014.060557.

17. Lee B.T., Youn M.H., Paul R.K., Lee K.H., Song H.Y. (2007): In situ synthesis of spherical BCP nanopowders by microwave assisted process. Materials Chemistry and Physics, 104, 249-253. doi: 10.1016/j.matchemphys.2007. 02.009 .

18. Xu Y., Geng Z., Gao Z., Zhou X., Li B., Cui Z., Zhu S., Liang Y., Li Z., Yang X. (2017): Effects of both Sr and Mg substitution on compositions of biphasic calcium phosphate derived from hydrothermal method. Applied Ceramic Technology, 15(1), 210-222. doi: 10.1111/ijac.12771.

19. Hong M.H., Kim S.M., Lee Y.K. (2017): Mechanical and Biological Properties of Biphasic Calcium Phosphate Scaffold depending on Different Nanoparticle Fabrication Methods. Journal of Ceramic Science and Technology, 8(4), 541-546. doi: 10.4416/JCST2017-00033.

20. Florek M., Fornal E.,. Romero P.G, Zieba E., Paszkowicz W., Lekki J., Nowak J., Kuczumow A. (2009): Complementary microstructural and chemical analyses of Sepia officinalis endoskeleton. Materials Science and Engineering C, 29, 1220-1226. doi: 10.1016/j.msec.2008.09.040.

21. Zhou G.T, Yao Q.Z., Ni J., Jin G. (2009): Formation of aragonite mesocrystals and implication for biomineralization. American Mineralogist, 94, 293-302. doi: 10.2138/ am.2009.2957.

22. Thien D.V.H., Thuyen N.T.B., Quyen T.T.B., Chiem N.H., Thuy V.P.D., Viet P.H. (2021): Microwave-assisted synthesis of nanorod hydroxyapatite from eggshells. Vietnam Journal of Science, Technology and Engineering, 63(1), 3-6. doi: 10.31276/VJSTE.63(1).03-06.

23. Poštić S.D. (2014): X-Ray Diffraction Technique in the Analysis of Phases of Hydroxylapatite and Calcium Phosphate in a Human Jaw. International Journal of BioMedicine, 4(2), 109-113.

24. Hou P.J., Lee C.Y., Ou K.L., Lan W.C., Chou Y.C., Lin H.Y., Chao H.W., Huang B.H., Saito T., Tsai H.Y., Yang T.S., Walinski C.J., Ruslin M. (2021): Calcium Release from Different Toothpastes after the Incorporation of Tricalcium Phosphate and Amorphous Calcium Phosphate. Applied Sciences, 11(1848), 1-12. doi: 10.3390/app11041848.

25. D' Arros, C., Rouillon, T., Veziers, J., Malard, O., Borget, P., Daculsi, G. (2020): Bioactivity of Biphasic Calcium Phosphate Granules, the Control of a Needle-Like Apatite Layer Formation for Further Medical Device Developments. Frontiers in Bioengineering and Biotechnology, 7, 462. doi: 10.3389/fbioe.2019.00462. 